\title{
Interface pressure and cutaneous hemoglobin and oxygenation changes under ischial tuberosities during sacral nerve root stimulation in spinal cord injury
}

\author{
Liang Qin Liu, MB; ${ }^{1-2}$ Graham P. Nicholson, PhD; ${ }^{3}$ Sarah L. Knight, PhD; ${ }^{1-2}$ Ramesh Chelvarajah, MRCS; $^{1}$ \\ Angela Gall, MRCP; ${ }^{4}$ Fred R. I. Middleton, FRCP; ${ }^{4}$ Martin W. Ferguson-Pell, PhD; ${ }^{3}$ Michael D. Craggs, PhD ${ }^{1-2 *}$ \\ ${ }^{1}$ Spinal Research Centre, Royal National Orthopaedic Hospital (RNOH), Stanmore, United Kingdom; ${ }^{2}$ Institute \\ of Urology, University College London, London, United Kingdom; ${ }^{3}$ Aspire Centre for Disability Sciences, University \\ College London, London, United Kingdom; ${ }^{4}$ The London Spinal Cord Injuries Centre, RNOH, Stanmore, United Kingdom
}

\begin{abstract}
Noninvasive functional magnetic stimulation (FMS) of the sacral nerve roots can activate gluteal muscles. We propose the use of sacral anterior root stimulator (SARS) implants to prevent ischial pressure ulcers in the spinal cord injury (SCI) population. In this study, we (1) investigated the acute effects of sacral FMS on ischial pressure, skin blood content, and oxygenation changes in people with SCI and demonstrated the utility of FMS as an assessment tool, and (2) showed that similar effects are possible with electrical stimulation via a SARS implant. Results indicated that sacral nerve root stimulation, either by FMS or implanted electrical stimulation, induced sufficient gluteus maximus contraction to significantly change subjects' ischial pressures and cutaneous hemoglobin and oxygenation during sitting. In addition to these beneficial acute effects, chronic stimulation via a SARS implant may build gluteal muscle bulk and prevent or reduce pressure ulcers in the SCI population.
\end{abstract}

Key words: functional electrical stimulation, functional magnetic stimulation, gluteal muscles, ischial pressure change, ischial tuberosity, pressure ulcer, rehabilitation, sacral nerve root stimulation, seat interface pressure, spinal cord injury, tissue reflectance spectrometry.

\section{INTRODUCTION}

An estimated 250,000 persons have spinal cord injury (SCI) in the United States (http://images.main.uab.edu/ spinalcord/pdffiles/factsfig.pdf). In the United Kingdom, about 700 new cases of traumatic SCI occur each year, for a total prevalence of approximately 50,000 persons with an SCI that results in permanent paralysis [1]. Up to 85 percent of persons with SCI will develop a pressure ulcer (PU) during their lifetime. The reported annual incidence of PUs is approximately 23 to 33 percent [2-5]. PUs represent a very significant cost burden for the health and social care systems. The cost of treating a PU varies from $£ 1,064$ (Grade $1 \mathrm{PU}$ ) to $£ 10,551$ (Grade $4 \mathrm{PU}$ ) in the United Kingdom [6] ( $£ 1$ = approximately \$1.89). In addition to high morbidity, PUs also prolong immobility, delay rehabilitation, impose immense personal cost, and have a huge social impact because of the associated loss of independence and exclusion from activities of daily living.

\footnotetext{
Abbreviations: ASCII = American Standard Code for Information Interchange, $\mathrm{C}=$ cervical, $\mathrm{CI}=$ confidence interval, FES = functional electrical stimulation, FMS = functional magnetic stimulation, $\mathrm{Hb}=$ hemoglobin, IHB = index of cutaneous hemoglobin, IOX = index of oxygenation, IT = ischial tuberosity, PU = pressure ulcer, $\mathrm{S}=$ sacral, SARS = sacral anterior root stimulator, SCI = spinal cord injury, SEM = standard error of mean, $\mathrm{T}=$ thoracic, TRS = tissue reflectance spectrometry.

*Address all correspondence to Professor Michael D. Craggs, Spinal Research Centre, Royal National Orthopaedic Hospital, Stanmore, Middlesex HA7 4LP, United Kingdom. +44-20-8909-5343; fax: +44-20-8909-5343;

Email: michael.craggs@ucl.ac.uk

DOI: 10.1682/JRRD.2005.08.0135
} 
Despite a great deal of research on the etiology of PUs, the relative importance of causative factors remains unclear. More than 200 factors that contribute to PU development have been identified in the literature [7]. Prolonged localized pressure coupled with loss of sensation to ischemia below the level of the lesion is considered the most important factor. Following the acute stages of SCI, patients are generally mobilized in a wheelchair. Consequently, the ischial tuberosity (IT) is the most vulnerable site for PUs in people with SCI who use wheelchairs. Approximately one-third of PUs in people with SCI are associated with sitting in a wheelchair [8].

Once a PU forms, it is costly, difficult to repair fully, and results in a risk of ulcer recurrence, particularly in people with SCI. Undoubtedly, prevention of PUs is very important. Specialized cushions that reduce seat pressures combined with pressure-relief movements in which the patient performs "push-ups" or "leans forward" are presently considered the best options for preventing PUs in people with SCI [9-12]. However, pressure-relief movements require good upper-limb strength and continued motivation, which may not always be present in persons with high-level lesions. Although many different kinds of wheelchair cushions have been evaluated for their effectiveness in reducing seat interface pressures to prevent PUs [11-14], these studies have generally concluded that seat cushions alone do not adequately relieve pressure during continuous sitting. In view of these limitations, alternative means of PU prevention need to be investigated.

Levine et al. investigated dynamic changes in seat interface pressure using surface functional electrical stimulation (FES) of the gluteus maximus [15-17]. Interestingly, these results indicated that FES could change the shape of loaded buttocks and thereby significantly reduce pressure under the ITs and redistribute it over other parts of the seat interface. In an another study, the effect of surface electrical stimulation on skin blood flow was investigated in four participants with SCI. The investigators applied scintigram with intradermal injections of radioactive tracer at each IT to determine the skin blood flow [18]. They found that skin blood flow increased during stimulation for all the participants. Similarly, Kett et al. measured the muscle blood flow during surface FES of gluteal muscles on eight nondisabled subjects and six subjects with SCI [19]. In that study, the investigators made a washout of an intramuscular injection of radioactive Xenon133 $1 \mathrm{in}$. lateral to the IT to measure blood flow in muscle and subcutaneous tissue. They demonstrated that blood flow was greater during 2 min stimulation for all subjects. Taken as a whole, these studies indicate that FES of the gluteal muscles might be useful for PU prevention. However, these studies are constrained by the invasive procedures for blood flow measurement and the repeated application of large electrodes over the buttocks for gluteal muscle activation. Long-term practicality and patient compliance with these techniques are problematic.

Most recently, implanted muscular FES of gluteal muscles has been shown to benefit seat pressure and tissue oxygenation [20]; an anal probe that stimulates gluteal muscles was also reported to heal ischial PUs [21]. Alternatively, an implanted sacral nerve electrical stimulator device may be a more practical solution especially if its utility can be demonstrated noninvasively. For this purpose, noninvasive functional magnetic stimulation (FMS) of the sacral nerve roots can effectively and noninvasively contract gluteal and pelvic floor muscles [22-23]. FMS has advantages over surface FES because of its noninvasive deep penetration. With use of a magnetic coil and application of a time-varying magnetic field to stimulate the nerve trunk, one can create an electrical current that stimulates neuromuscular tissue in a manner similar to FES [24]. For long-term stimulation of the gluteal muscles, electrical stimulation through implanted electrodes to the sacral nerve roots may more effectively prevent ischial PUs in wheelchair users with SCI. Recently, we used FMS to investigate the dynamic effects of sacral nerve root stimulation on ischial pressure changes in nondisabled people. Our results demonstrated that ischial pressure significantly decreased during optimal stimulation [23]. However, we reported neither the effects of FMS on people with SCI nor the tissue hemodynamic changes during FMS.

In this study, we aimed to-

1. Investigate the dynamic effects of sacral FMS on seat interface pressure, cutaneous hemoglobin, and oxygenation in people with SCI and demonstrate the utility of FMS as an assessment tool.

2. Show that similar effects are possible with sacral electrical stimulation via a sacral anterior root stimulator (SARS) implant in people with SCI (SARS implants are currently used for bladder emptying).

\section{METHODS}

The study protocol was approved by the local ethics committee. All subjects gave their informed consent. 
For the sacral FMS study, we included subjects who had suprasacral SCI (complete/incomplete) and were between 18 and 65 years old; we excluded individuals who were pregnant or using a cardiac pacemaker, which are contraindications for magnetic stimulation.

For the SARS implant study, we included subjects who had suprasacral complete SCI, a SARS implant, and were 18 to 65 years old. Subjects with current PUs over the gluteal region or a history of severe autonomic dysreflexia were excluded from both studies.

Five males with SCI (age 23 to 56 yr, level of injury between fourth cervical [C4] and eleventh thoracic [T11] complete/incomplete, duration of injury 2 to $12 \mathrm{yr}$ ) were recruited for the sacral FMS study (Table 1). Five males and one female with SCI (age 34 to $62 \mathrm{yr}$, level of injury between T3 and T11 complete, duration of injury 9 to $24 \mathrm{yr}$ ) were recruited for the SARS implant study (Table 2).

\section{Sacral Functional Magnetic Stimulation}

FMS was delivered by a repetitive magnetic stimulator (MagPro, Dantec Dynamics A/S, Skovlunde, Denmark) with a large circular coil (120 mm diameter, producing a maximal strength of $2 \mathrm{~T}$ ) that was placed over the sacrum area (Figure 1). To obtain smooth tetanic contraction of the gluteal muscles, we used stimulation frequencies ranging from 15 to 25 pps and increased intensity from 10 to 80 percent in 5 percent steps (stimulation strength is indicated as percentage of the maximal output of stimulator) for $2 \mathrm{~s}$. The optimal FMS parameters for the individual subjects are described in Table 3.

The optimal coil position for sacral nerve root stimulation was determined by mapping the gluteal muscle response [22-23]. The coil was placed over various points of a grid pattern that ranged from the level of the iliac crest to $10 \mathrm{~cm}$ below and $8 \mathrm{~cm}$ to either side of midline.

\section{Sacral Electrical Stimulation via Sacral Anterior Root Stimulator Implant}

Sacral electrical stimulation was applied bilaterally in the subjects through an implanted Finetech-Brindley (Finetech Medical Ltd, Welwyn Garden City, Hertfordshire, United Kingdom) SARS implant (currently used for bladder emptying [25-27]). Before the experiment, subjects were asked to empty their bladders and bowels. Then, only the second sacral (S2) nerve root was stimulated. To obtain smooth tetanic contraction of the gluteal muscles, we used a stimulation frequency of 20 pps at a pulse width that varied from 8 to $800 \mu \mathrm{s}$ for $8 \mathrm{~s}$. We selected the lowest amplitude of 1 for all subjects to avoid activating deeper muscles or organs such as the bladder and bowel. The optimal stimulation parameters for all six subjects were a duration of $5 \mathrm{~s}$, frequency of $20 \mathrm{~Hz}$, and amplitude of 1 . The optimal pulse widths for each subject were-

- Subject 1: $256 \mu$ s.

- Subject 2: $128 \mu \mathrm{s}$.

- Subject 3: $600 \mu \mathrm{s}$.

- Subject 4: $256 \mu$ s.

- Subject 5: $128 \mu \mathrm{s}$.

- Subject 6: $512 \mu \mathrm{s}$.

\section{Ischial Pressure Measurement}

Each subject sat in a wheelchair with fitted arm- and footrests. Ischial pressures were measured with an interface pressure mapping system $(36 \times 36$ cells at $10 \mathrm{~mm}$ pitch, XSENSOR Technology Corporation, Calgary, Alberta, Canada). The seat pressure mat was placed between the subject and the standard foam cushion (high resilience foam, density $45 \mathrm{~kg} / \mathrm{m}^{3}$ ). Before the study began, the seat pressure mat was calibrated according to the manufacturer's instructions. An initial data set was recorded once the subjects had stabilized in a standard sitting position that was defined as (1) backrest-to-seat angle of at least $80^{\circ}$ and

Table 1.

Baseline characteristics of five male subjects with spinal cord injury.

\begin{tabular}{ccccclcc}
\hline Subject & Age & $\begin{array}{c}\text { Weight } \\
\mathbf{( k g )}\end{array}$ & $\begin{array}{c}\text { Height } \\
\mathbf{( m )}\end{array}$ & $\begin{array}{c}\text { Body Mass } \\
\text { Index }\end{array}$ & Injury Level & $\begin{array}{c}\text { Year of } \\
\text { Injury }\end{array}$ & $\begin{array}{c}\text { History of Ischial } \\
\text { Pressure Ulcer }\end{array}$ \\
\hline 1 & 35 & 75.1 & 1.76 & 24.24 & T7 complete & 1992 & Stage I (left) \\
2 & 56 & 92.3 & 1.87 & 26.39 & C3/4 incomplete & 2000 & No \\
3 & 49 & 72.2 & 1.71 & 24.69 & T5 complete & 2001 & No \\
4 & 23 & 82.2 & 1.91 & 22.53 & C5/6 complete & 2003 & No \\
5 & 46 & 114.3 & 1.82 & 34.51 & T10/11 complete & 2000 & No \\
\hline
\end{tabular}


JRRD, Volume 43, Number 4, 2006

Table 2.

Baseline characteristics of six patients with spinal cord injury and sacral anterior root stimulator implant.

\begin{tabular}{cccccccccc}
\hline Subject & Age & Sex & $\begin{array}{c}\text { Weight } \\
\mathbf{( k g )}\end{array}$ & $\begin{array}{c}\text { Height } \\
\mathbf{( m )}\end{array}$ & $\begin{array}{c}\text { Body Mass } \\
\text { Index }\end{array}$ & Injury Level & $\begin{array}{c}\text { Year of } \\
\text { Injury }\end{array}$ & $\begin{array}{c}\text { History of Ischial } \\
\text { PU }\end{array}$ & $\begin{array}{c}\text { Roots } \\
\text { Implanted }\end{array}$ \\
\hline 1 & 34 & F & 57.0 & 1.66 & 20.70 & T7/8 complete & 1992 & No & S2, S3, S4 \\
2 & 41 & M & 78.6 & 1.78 & 24.81 & T4/5 complete & 1980 & Stage I PU (right) & S2, S3, S4 \\
3 & 38 & M & 72.5 & 1.83 & 21.85 & T4 complete & 1995 & No & S2, S3, S4 \\
4 & 50 & M & 71.1 & 1.82 & 21.46 & T3 complete & 1995 & Stage II PU (bilateral) & S2, S3, S4 \\
5 & 62 & M & 84.2 & 1.73 & 28.13 & T10/11 complete & 1982 & Stage I (left) & S2, S3, S4 \\
6 & 42 & M & 108.0 & 1.76 & 34.87 & T10 complete & 1995 & No & S2, S3, S4 \\
\hline \multicolumn{7}{l}{ F= female, M = male, PU = pressure ulcer, S = sacral, T = thoracic (number refers to vertebrae number). } & & \\
\hline
\end{tabular}

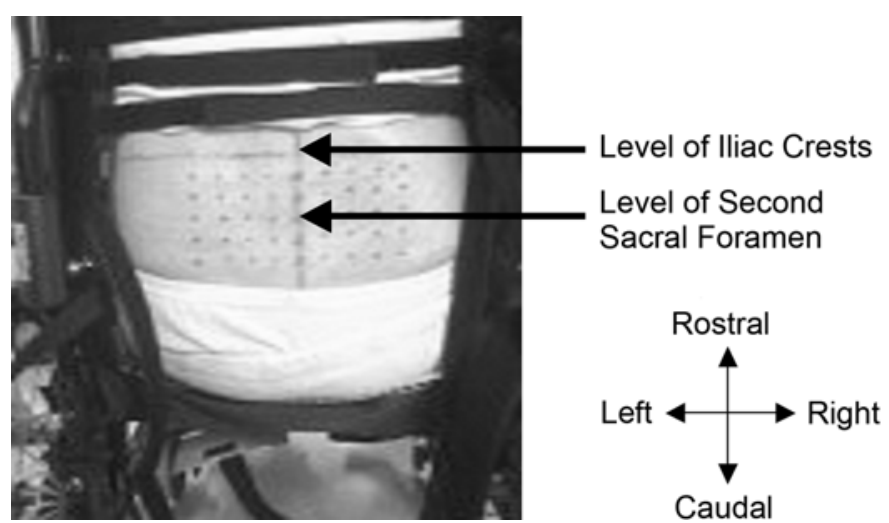

Figure 1.

Magnetic coil applied on the sacrum with a $2 \mathrm{~cm}$ pitch-grid drawn on skin.

(2) footrest adjustment such that thighs were parallel to the seat. Seat pressures were recorded before, during, and after stimulations. The sample rate of pressure mapping was $7 \mathrm{~Hz}$ frame/s. Real-time two-dimensional images of pressure distribution at the seat interface were produced with the graphical display software provided with the pressure mapping system and were saved on a personal computer.

All data were then converted to American Standard Code for Information Interchange (ASCII) format. The seat interface pressure readings were peak pressure and gradient at peak pressure. Peak pressure was defined as the highest individual sensor value under the ITs. Gradient at peak pressure was defined as the average difference among the highest sensor value and the values of the eight surrounding sensors. Pressure measurement data were analyzed by comparison of the peak pressure and gradient at peak pressure. Two-tailed paired $t$-test with 95 percent confidence interval (CI) was used for comparing the pressure parameters before and during stimulations. Statistical significance was defined as $\alpha=0.05$.
Table 3.

Optimal parameters of functional magnetic stimulation for $2 \mathrm{~s}$ in five subjects with spinal cord injury.

\begin{tabular}{ccc}
\hline Subject & $\begin{array}{c}\text { Frequency } \\
\text { (Hz) }\end{array}$ & $\begin{array}{c}\text { Intensity } \\
\mathbf{( \% )}\end{array}$ \\
\hline 1 & 25 & 60 \\
2 & 20 & 65 \\
3 & 20 & 60 \\
4 & 20 & 45 \\
5 & 20 & 55 \\
\hline
\end{tabular}

\section{Ischial Cutaneous Hemoglobin and Oxygenation}

We used a tissue reflectance spectrometer (TRS) (MCS521 spectrometer, Carl Zeiss, Germany) in the visible spectrum to measure index of hemoglobin (IHB) and index of oxygenation (IOX) under the ITs [28-30]. The TRS uses the characteristic absorption of light by the constituents of skin to measure the various constituents present. The theory of TRS is based on a simple anatomical model [28]. Light passes through the epidermis and a plexus of blood vessels in the dermis (hemoglobin [Hb] layer) before being reflected off collagen in the lower dermis. Hb absorbs light with a characteristic curve that shows broad bands of absorption in the portion of the spectrum (Figure 2). Oxyhemoglobin has two maxima at the approximate wavelengths of 542 and $574 \mathrm{~nm}$. Deoxyhemoglobin shows a single maximum at the approximate wavelength of $545 \mathrm{~nm}$. Thus, TRS can theoretically produce information about both the amount of $\mathrm{Hb}$ present and its degree of oxygenation.

The TRS was always allowed to equilibrate for $30 \mathrm{~min}$ before the experiment. Each subject sat in a wheelchair with fitted arm- and footrests. A flexible thin flat optical probe (developed by Aspire Centre for Disability Science, University College London, United Kingdom) was placed on the skin under the left or right IT with double-sided 


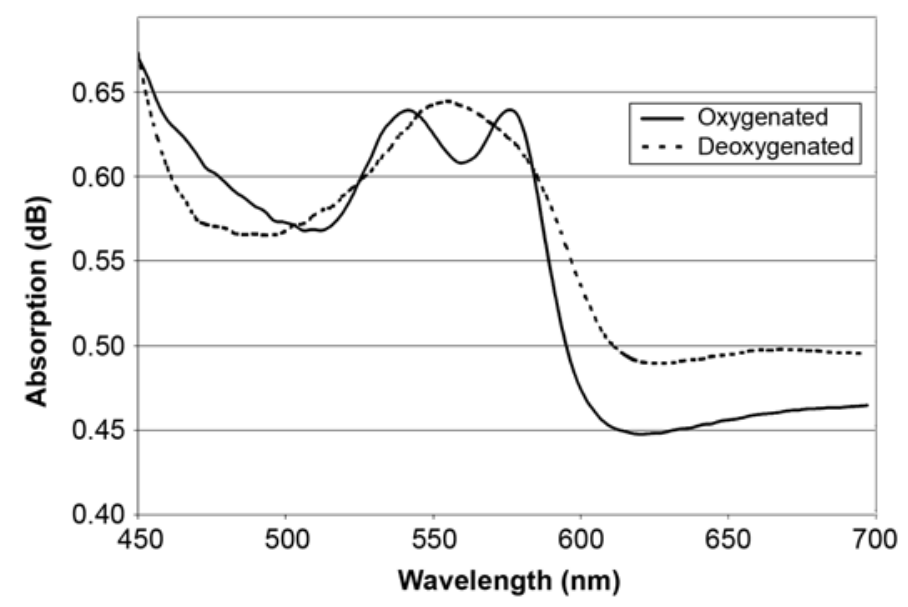

Figure 2.

Spectral absorption response of hemoglobin (oxygenated and deoxygenated).

adhesive tape. This probe incorporated two plastic optical fibers ( $1 \mathrm{~mm}$ diameter with $1 \mathrm{~mm}$ spacing) that were bonded in a Shore D60 flat flexible polyurethane sheath (Flexane 60L, Devcon Ltd, Ireland) for transmission of incident and reflected light from the skin surface to the TRS. Theoretical skin-penetration depth was $500 \mu \mathrm{m}$. The left or right IT was randomly selected. Spectral response of $\mathrm{Hb}$ was continually monitored before, during, and after optimal stimulation. The sample rate for data acquisition of a full spectrum was $2 \mathrm{~Hz}$ with a $500 \mathrm{~ms}$ integration time and 0.5 s cycle time.

The absorption values for each $1 \mathrm{~nm}$ wavelengthincrement between 450 and $650 \mathrm{~nm}$ were stored on a personal computer for offline processing. After data acquisition, the data were converted to ASCII text and exported to Microsoft Excel 2000 (Microsoft Corporation, Redmond, Washington). IHB and IOX were calculated with a modified version of methods by Feather et al. [31-32] and Hagisawa et al. [28]. Equations for the calculation of IHB and IOX for this study were

$$
\mathrm{IHB}=\left[\left(\frac{A 546-A 521}{25}\right)-\left(\frac{A 546-A 521}{20}\right)\right] \frac{100}{2}
$$

and

$$
\mathrm{IOX}=\left[\left(\frac{A 566-A 577}{9(\mathrm{IHB})}\right)-\left(\frac{A 577-A 546}{11(\mathrm{IHB})}\right)\right] \frac{100}{2},
$$

where $A$ is the absorption value at the specified wavelength (nanometer) in the TRS.
No melanin compensation was used. However, all subjects were Caucasian with very little melanin in the skin covering the ITs. We analyzed IHB and IOX data by comparing IHB and IOX before and during stimulation when subjects were sitting in the chair. When subjects are sitting, IHB would be close to 0 . To prevent negative IOX and simplify IOX interpretation, we offset all IHB values by 1 . For the $2 \mathrm{~s}$ magnetic stimulation, IHB and IOX were averaged over four frames before and four frames during stimulation; for the $8 \mathrm{~s}$ electrical stimulation via SARS implant, IHB and IOX were averaged over 16 frames before and 16 frames during stimulation; we used a twotailed paired $t$-test with 95 percent CI to compare IHB and IOX before and during each stimulation. Statistical significance was set at $\alpha=0.05$.

\section{RESULTS}

\section{Sacral Functional Magnetic Stimulation Study}

\section{Peak Pressure and Gradient at Peak Pressure}

The five subjects with SCI tolerated FMS well and experienced no adverse effects. We determined peak pressure under the ITs for each of the six frames within a data set and averaged the six frames. The difference between resting and optimal stimulated peak pressures at the ITs was statistically significant. The results for the individual subjects are summarized in Table 4.

For the group $(n=5)$, the difference between resting and optimal stimulated peak pressures at the ITs was statistically significant; with optimal stimulation, an average 27 percent reduction in peak pressure and 27 percent reduction in gradient at peak pressure were achieved. Peak pressures decreased during FMS as compared with baseline (mean \pm standard error of mean $[\mathrm{SEM}]=157.6 \mathrm{mmHg} \pm 16.0[21.0 \mathrm{kPa} \pm 2.1]$ during stimulation vs $115.5 \mathrm{mmHg} \pm 11.5[15.4 \mathrm{kPa} \pm 1.5]$ at rest, $p=0.006$, two-tailed paired $t$-test) (Figure 3(a)). Similarly, the gradient at peak pressure decreased during FMS as compared with baseline (mean $\pm \mathrm{SEM}=30.0 \mathrm{mmHg} / \mathrm{cm} \pm$ $2.7[3.9 \mathrm{kPa} / \mathrm{cm} \pm 0.4]$ during stimulation vs $41.2 \mathrm{mmHg} /$ $\mathrm{cm} \pm 6.4[5.5 \mathrm{kPa} / \mathrm{cm} \pm 0.9]$ at rest, $p=0.030$, paired twotailed $t$-test) (Figure 3(b)). The optimal response was achieved when the coil was located at S2 level (about $6 \mathrm{~cm}$ below the iliac crest). For bilateral pressure decrease, the optimal coil position was at midline (except for one subject with sclerosis); for ipsilateral pressure decrease, the optimal position was 2 to $4 \mathrm{~cm}$ lateral to midline. Increased FMS intensity was associated with greater reductions in peak pressure, as would be expected. 
JRRD, Volume 43, Number 4, 2006

Table 4.

Pressures and skin blood circulation under ischial tuberosities before and during functional magnetic stimulation (FMS) of five subjects with spinal cord injury. Drop represents change from before to during FMS.

\begin{tabular}{|c|c|c|c|c|c|c|c|c|c|c|}
\hline \multirow{2}{*}{ Subject } & \multicolumn{3}{|c|}{ Peak Pressure (mmHg) } & \multicolumn{3}{|c|}{ Gradient at Peak Pressure $(\mathrm{mmHg} / \mathrm{cm})$} & \multicolumn{2}{|c|}{ IHB } & \multicolumn{2}{|c|}{ IOX } \\
\hline & Before & FMS & Drop & Before & FMS & Drop & Before & FMS & Before & FMS \\
\hline 1 & 188.0 & 124.0 & 64.0 & 55.0 & 37.0 & 18.0 & 0.99 & 1.19 & 1.96 & 3.72 \\
\hline 2 & 97.3 & 80.3 & 17.0 & 39.0 & 33.0 & 6.0 & 1.06 & 1.51 & 0.32 & 1.00 \\
\hline 4 & 133.5 & 105.5 & 28.0 & 26.0 & 22.0 & 4.0 & 1.05 & 1.20 & 0.28 & 0.82 \\
\hline 5 & 186.0 & 151.0 & 35.0 & 29.0 & 26.0 & 3.0 & 1.04 & 1.25 & 0.17 & 1.21 \\
\hline
\end{tabular}

(a)

(b)
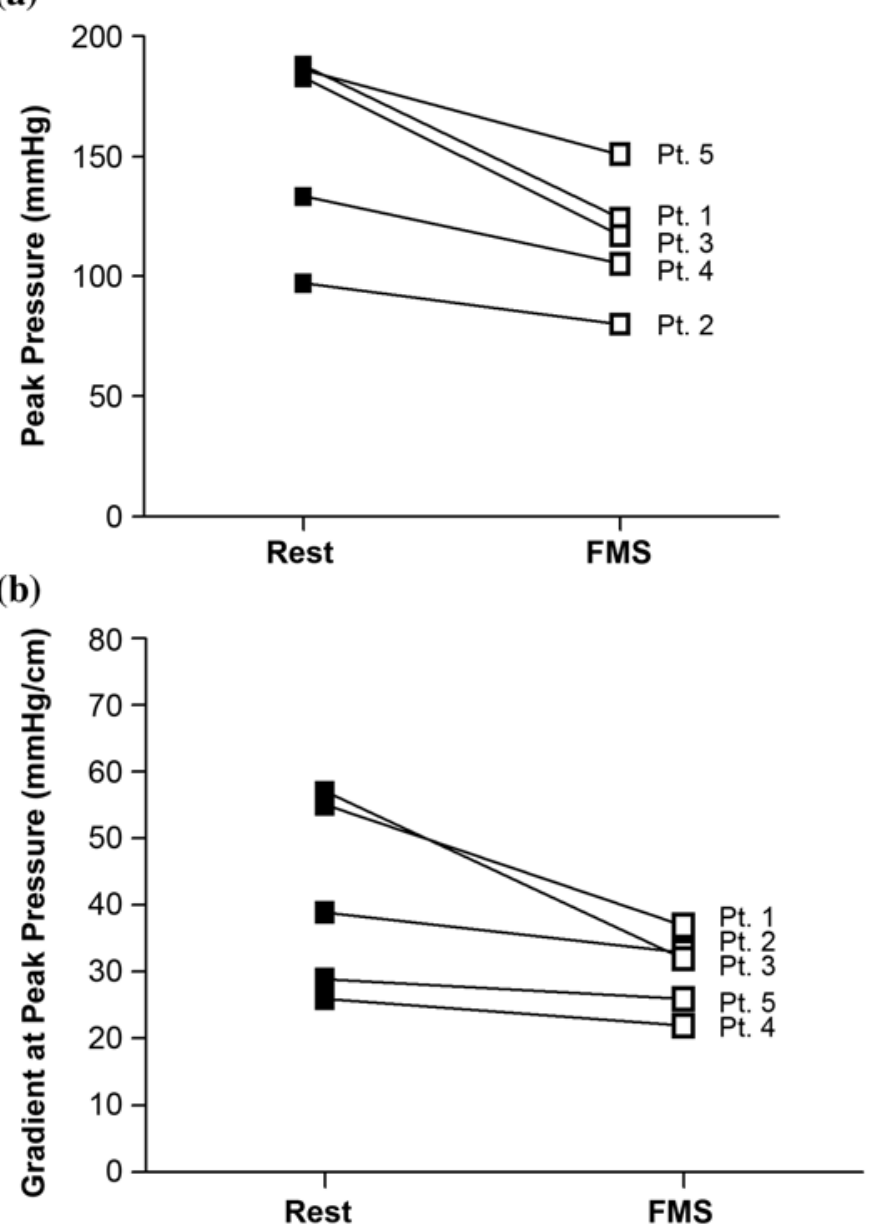

Figure 3.

(a) Peak pressure and (b) gradient at peak pressure before (rest) and during optimal functional magnetic stimulation (FMS) in five participants (Pt.) with spinal cord injury and a sacral anterior root stimulator implant. Values shown are mean \pm standard error of measurement.
Cutaneous Hemoglobin and Oxygenation

The IHB and IOX results for the individual subjects with SCI are shown in Table 4. In all five subjects, IHB and IOX increased during optimal stimulation when they were seated, which indicates increased skin blood content and IOX during stimulation.

For the group ( $n=5)$, the difference between resting and optimal stimulated IHB and IOX were significant (mean \pm SEM $=$ IHB, $1.04 \pm 0.01$ before stimulation vs $1.25 \pm 0.07$ during optimal stimulation, $p=0.04$, two-tailed paired $t$-test; IOX, $0.68 \pm 0.03$ before stimulation vs $1.52 \pm$ $0.50, p=0.03$ during stimulation, two-tailed paired $t$-test).

\section{Sacral Electrical Stimulation via Sacral Anterior Root Stimulator Study}

\section{Peak Pressure and Gradient at Peak Pressure}

All six subjects with SCI who had a SARS implant completed the study and reported no muscular, skeletal, or bladder complications. Bilateral S2 stimulation caused a palpable contraction of the gluteus maximus and associated mild hip and leg movements. Initial data analysis showed no significant differences between left and right IT pressure, and therefore, bilateral values were averaged for each subject. The results for the individual subjects are summarized in Table 5.

With optimal stimulation, an average 30 percent reduction in peak pressure was observed (mean \pm SEM = $148.9 \mathrm{mmHg} \pm 8.1[19.9 \mathrm{kPa} \pm 1.1]$ at rest vs $105.5 \mathrm{mmHg} \pm 7.9[14.1 \mathrm{kPa} \pm 1.1]$ during stimulation, $p=0.01$, two-tailed paired $t$-test) (Figure 4(a)). A 38 percent reduction in gradient at peak pressure (mean \pm $\mathrm{SEM}=51.0 \mathrm{mmHg} / \mathrm{cm} \pm 8.0[6.8 \mathrm{kPa} / \mathrm{cm} \pm 1.1]$ at rest vs $32.8 \mathrm{mmHg} / \mathrm{cm} \pm 6.4[4.4 \mathrm{kPa} / \mathrm{cm} \pm 0.9]$ during stimulation, $p=0.03$, two-tailed paired $t$-test) was obtained 
Table 5.

Pressures and skin blood circulation under ischial tuberosities before (rest) and during functional electrical stimulation (FES) of six subjects with spinal cord injury and sacral anterior root stimulator implant.

\begin{tabular}{|c|c|c|c|c|c|c|c|c|}
\hline \multirow[t]{2}{*}{ Subject } & \multicolumn{2}{|c|}{$\begin{array}{l}\text { Peak Pressure } \\
\text { (mmHg) }\end{array}$} & \multicolumn{2}{|c|}{$\begin{array}{c}\text { Gradient at Peak } \\
\text { Pressure (mmHg/cm) }\end{array}$} & \multicolumn{2}{|c|}{ IHB } & \multicolumn{2}{|c|}{ IOX } \\
\hline & Rest & FES & Rest & FES & Rest & FES & Rest & FES \\
\hline 2 & 148.0 & 102.5 & 62.0 & 23.0 & 0.99 & 1.05 & 0.95 & 1.02 \\
\hline 3 & 152.3 & 108.0 & 54.0 & 52.0 & 0.95 & 0.99 & 0.93 & 3.54 \\
\hline 5 & 127.8 & 76.5 & 21.0 & 14.0 & 0.95 & 1.07 & 0.94 & 2.01 \\
\hline 6 & 150.6 & 134.2 & 33.0 & 28.0 & 0.96 & 1.05 & 0.91 & 2.31 \\
\hline$\overline{\text { Mean } \pm \text { SEM }}$ & $148.9 \pm 8.1$ & $105.5 \pm 7.9^{*}$ & $51.0 \pm 8.0$ & $32.8 \pm 6.4^{\dagger}$ & $0.8 \pm 0.2$ & $0.9 \pm 0.1^{*}$ & $1.1 \pm 0.2$ & $3.0 \pm 0.6^{\dagger}$ \\
\hline
\end{tabular}

(a)

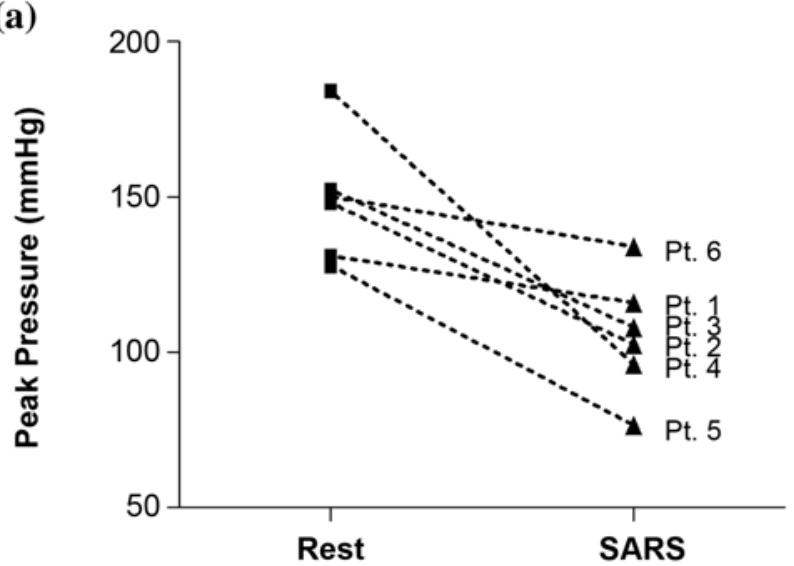

(b)

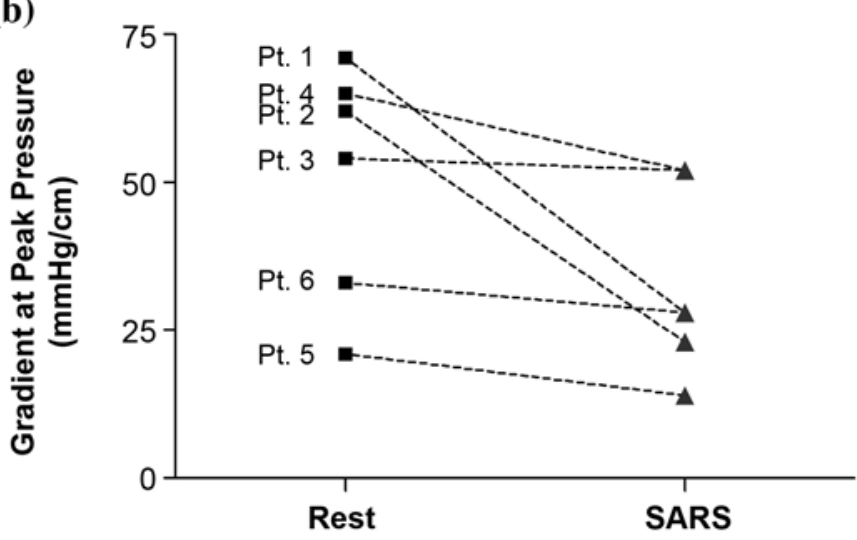

Figure 4.

(a) Peak pressure and (b) gradient at peak pressure before (rest) and during optimal stimulation in six participants (Pt.) with spinal cord injury and a sacral anterior root (SARS) stimulator implant. Values shown are mean \pm standard error of mean.
(Figure 4(b)). Increased pulse width of sacral nerve root stimulation produced greater reduction in peak pressure, which stabilized after the maximum response was reached. Maximum reduction in peak pressure was achieved at a stimulation pulse width that varied from 64 to $600 \mu$ s across all subjects. As a group, the maximum reduction in peak pressure was obtained at a $256 \mu \mathrm{s}$ stimulation pulse width.

\section{Cutaneous Hemoglobin and Oxygenation}

Figure 5 shows one subject's typical trace of IHB and IOX before, during, and after stimulation via a SARS implant. The results of IHB and IOX for the individual subjects are shown in Table 5.

For the group ( $n=6)$, the difference between resting and optimal stimulated IHB and IOX were significant (mean \pm SEM $=$ IHB, $0.8 \pm 0.2$ before stimulation vs $0.9 \pm 0.1$ during stimulation, $p=0.005$, two-tailed paired $t$-test; IOX, $1.1 \pm 0.2$ before stimulation vs $3.0 \pm 0.6$ during stimulation, $p=0.02$, two-tailed paired $t$-test) (Figure 6).

\section{DISCUSSION}

Our results demonstrate that S2 nerve root stimulation by FMS or through an implanted electrical stimulator can induce gluteal muscle contractions sufficient to achieve statistically and clinically significant ischial pressure reductions and cutaneous blood circulation increases 

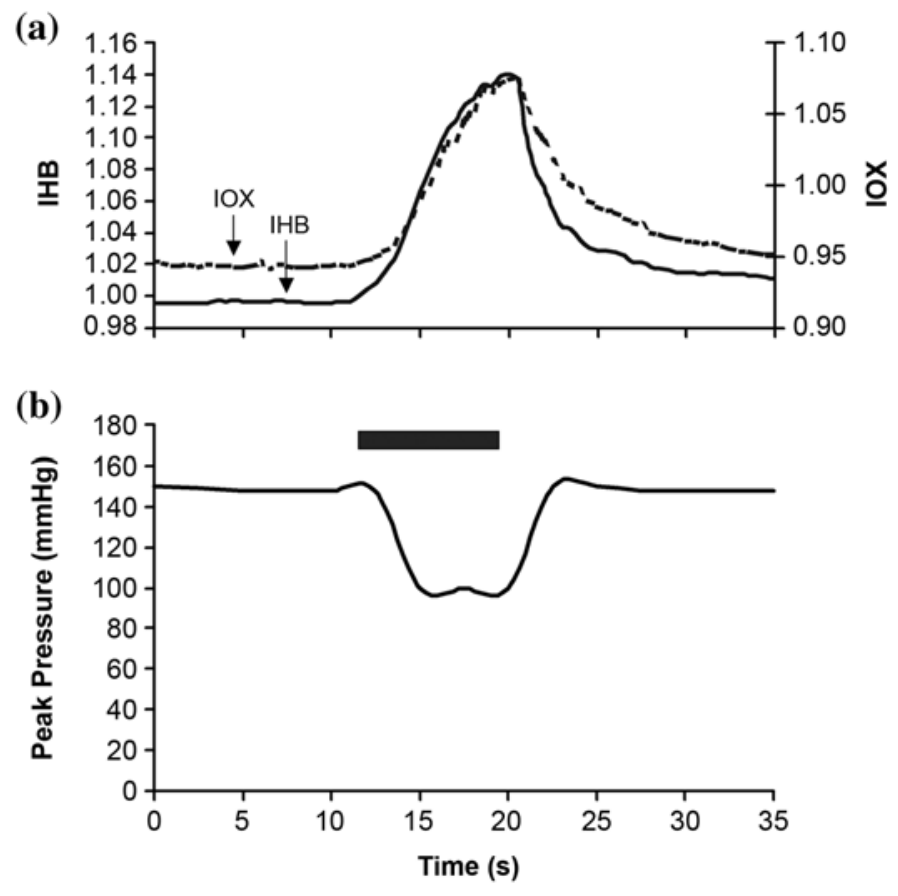

Figure 5.

(a) Index of cutaneous hemoglobin (IHB) and index of oxygenation (IOX) and (b) peak pressure in one male subject with spinal cord injury (subject 2) before, during (solid bar), and after functional electrical stimulation of the second sacral nerve roots via sacral anterior root stimulator implant.

during sitting. During optimal magnetic stimulation in the noninvasive magnetic stimulation study, maximum effects were obtained at the approximately S2 foramen level in all five subjects with SCI, which corresponds to a study on FMS in nondisabled people [23]. With electrical stimulation through the SARS implant, maximum reduction in peak pressure was obtained when the S2 nerve was stimulated with a pulse width between 64 and $600 \mu \mathrm{s}$, a frequency of 20 pps, and an amplitude of " 1. ."

The magnitude of peak pressure reductions in this study were greater than those Levine et al. produced with surface electrical stimulation of the gluteal muscles [16]. One possible explanation for this discrepancy is the two different types of stimulation that were used. The S2 nerve root stimulation used in our study efficiently activates the entire neuromuscular bundle, while FES of the gluteus maximus with surface electrodes only activates certain muscle fiber regions. The gluteus maximus has been considered difficult to stimulate with surface electrodes because of its greater mass and adipose tissue covering. The magnitude of peak pressure reductions with FMS in our study was greater than in another study that used FMS (a)

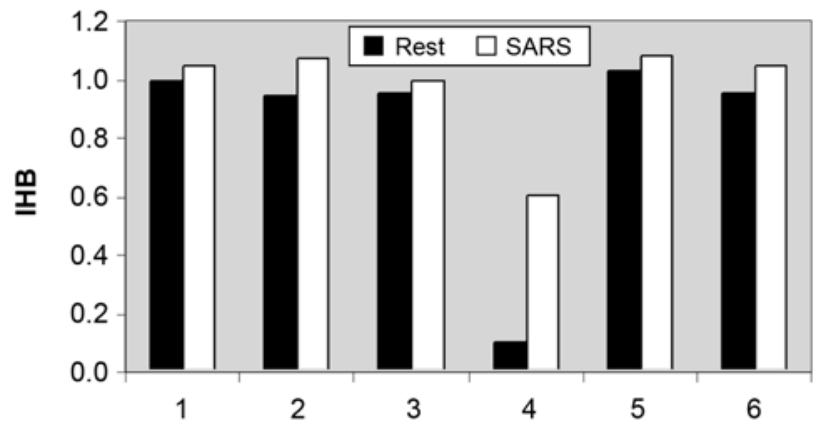

(b)

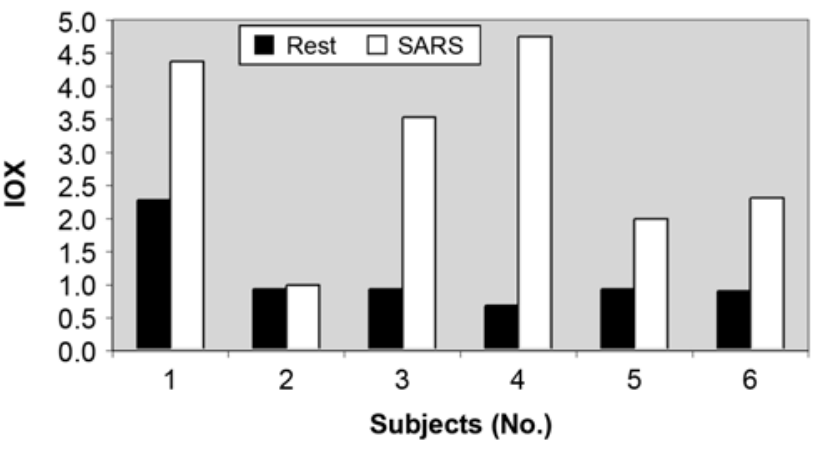

Figure 6.

(a) Index of cutaneous hemoglobin (IHB) and (b) index of oxygenation (IOX) at rest and during optimal stimulation via sacral anterior root stimulator (SARS) implant in six subjects with spinal cord injury.

in five nondisabled individuals [23]. This greater pressure reduction may be partly due to decreased compliance of gluteal tissue or increased tolerance of relatively stronger stimulation in SCI. In fact, Levine et al. looked at pressure changes on different seat surfaces and demonstrated that pressure change increased as the seat surface became less compliant [16]. Nevertheless, our results suggest that sacral nerve root stimulation may be more beneficial for subjects already experiencing gluteal muscle wasting.

Following an SCI, the interruption of spinal vasomotor pathways results in the loss of vasomotor control over skeletal muscle, skin, etc., which lowers the tone of the vascular bed below the level of the lesion. The impaired vascular patency causes the vessels to be less able to withstand normal loading conditions. Concurrent with the loss of capillary networks, because of lost muscle bulk, the volume of blood in the tissues is reduced [20]. While microcirculation is crucial for tissue viability in terms of supply of oxygen and nutrients and removal of waste products, interrupted microcirculation leads to ischemia and local tissue starvation, which consequently leads to greater risk of PU formation [33]. Individuals with SCI 
have many aspects of vascular changes that include reduced blood flow and impaired vascular reactivity [34]. Experimental studies have reported that in a high risk area for PU, occlusion of skin blood flow occurred at significantly lower external skin pressures in SCI versus nondisabled individuals [35]. Mawson et al. studied tissue oxygenation at the sacrum in individuals with SCI and found that their levels in a supine position were markedly lower than in nondisabled controls [36]. These findings suggest that circulatory dysfunction in individuals with SCI contributes to their susceptibility to PUs.

TRS is a noninvasive technique for IHB and IOX measurement. By using TRS, Hagisawa et al. investigated the reactive hyperemia response in the skin of the greater trochanter of nondisabled subjects and subjects with SCI and found that the reflow rate after loading was slower in the subjects with SCI [28]. In our study, we applied TRS to measure IHB and IOX. A thin flexible skin probe was placed under the IT without causing loading artifact; an advantage of this technique over conventional laser Doppler flowmetry is that the signal is not affected by movement associated with stimulation and muscle contraction. While the subjects sat on the foam cushion, compression of blood vessels occurred by external pressure. IHB values were nearly 1 before stimulation in the seated subjects, which signified skin blanching. During optimal stimulation, cutaneous $\mathrm{Hb}$ and oxygenation increased under the IT in all subjects. These results agree with those of Levine et al. who compared eight nondisabled subjects and six subjects with SCI in terms of blood flow of gluteal muscle as measured by Xenon133 clearance in response to electrical stimulation $(50 \mathrm{~Hz}$, with a duty cycle of $2 \mathrm{~s}$ on, $4 \mathrm{~s}$ off) [18]. All subjects showed increased muscle blood flow during stimulation, and the increase was greatest for the nondisabled group.

The exact mechanism of the increased IHB and IOX in our study is unclear. A dynamic "pressure relief" caused by gluteal muscle contraction and/or pelvic tilt, which dilates the microvessels that underlie the ischial skin, may be involved. Alternatively, increased blood perfusion may also have resulted from muscle contraction and allowed higher oxygen delivery rates and metabolite removal. Kindig et al. investigated the capillary red blood cell flux and distribution during skeletal muscle contraction in rats and found both parameters were increased during the muscle contraction [37]. Katz et al. showed that FES of the calf musculature of four subjects with SCI produced a mild increase in venous blood flow in the lower limbs. ${ }^{*}$ Scremin et al. reported an increase in cutaneous blood flow in the legs during electrical stimulation in subjects with SCI [38]. Most recently, Janssen and Hopman. found markedly increased blood flow in the femoral artery during 35 and $3 \mathrm{~Hz}$ electrical stimulation of 12 nondisabled subjects [39]. Although slightly greater contraction was reported for the 35 versus $3 \mathrm{~Hz}$ conditions, it was not significant. The authors proposed several mechanisms of increased blood flow, including a muscle pump effect, a cardiovascular response, and vasodilatation caused by local release of metabolites. In our study, we only applied one cycle of stimulation; therefore, a muscle pump effect cannot explain our results. Neuronal excitation and metabolic and cardiovascular responses may partially explain the increased blood perfusion. Measurements such as blood pressure and heart rate should be included in our future studies.

Because of the small sample, we did not find any relationship between pressure and body mass index. We also found no relationship between pressure and blood perfusion. Pressure reductions during SARS were slightly greater than during FMS. The discrepancy may be attributed to the different types of stimulation. FMS stimulates the sacral nerve roots, including posterior (sensory) and anterior roots (motor), while SARS only stimulates the sacral anterior roots. Additionally, the site of FMS is ill-defined compared with SARS via an implant. As a result, stimulation via a SARS implant is more effective for activating the gluteus maximus.

Because of FMS limitations, we could only apply stimulation for $2 \mathrm{~s}$ at $20 \mathrm{~Hz}$ for one burst. One should note that although IHB and IOX increased during stimulation, comparing the magnitude of change to the change with the 8 s SARS stimulation is difficult. Further studies should look at the mechanism of blood perfusion changes.

Compared with FES, in which electrical stimulation injects current into the body and results in axonal membrane depolarization, FMS occurs when a magnetic field induces an electrodynamic field; a time-varying magnetic field in turn creates a current that causes the membrane to depolarize and generate an action potential. The magnetic field itself does not stimulate the nerve but rather functions as the vehicle that causes icon flow. FMS has the advantage of being noninvasive and deeply penetrating, and

\footnotetext{
*Katz RT, Green D, Sullivan T, Yarkony G. Functional electrical stimulation for deep venous thrombosis in the spinal cord injury patient. Paper presented at the Annual Meeting of the American Congress of Physical Medicine and Rehabilitation; Oct 1986; Baltimore, MD.
} 
importantly, because magnetic fields preferentially activate larger fibers, FMS avoids the smaller sensory fibers that mediate pain [40]. On the other hand, FMS is limited by short stimulation duration, so long-term use is likely impractical. However, FMS can be used to assess the effects of S2 nerve root stimulation for future SARS implants. The SARS implant is a well-established procedure for bladder and/or bowel management in people with SCI. Although all implantable devices have potential risks, the SARS implant has the advantages of providing bladder management. Our experience, and that of others who have used implantable devices such as the Finetech-Brindley SARS, is that the SARS implant can offer many years of bladder and bowel management [26-27,41-42]. The SARS implant has also proven to be very cost-effective. For example, one of our subjects had been using the SARS implant for more than 20 years and benefited from, among other things, significant improvement in urinary tract infections and quality of life.

\section{CONCLUSIONS}

In people with SCI, S2 nerve root stimulation by FMS or through an implanted electrical stimulator can induce gluteal muscle contractions sufficient to achieve statistically and clinically significant ischial pressure reductions and cutaneous blood circulation increases during sitting. With FMS of the sacral nerve roots, maximal effects were obtained around the S2 foramen level. With electrical stimulation through the SARS implant, maximum reduction of peak pressure was obtained when the S2 nerve root was stimulated with a pulse width of 64 to $600 \mu \mathrm{s}$, frequency of $20 \mathrm{pps}$, and amplitude of " 1 ." Our group is currently investigating the long-term effects of sacral nerve root stimulation on tissue viability. Chronic stimulation via an implanted SARS may be useful for increasing gluteal muscle bulk, improving vascularization, and ultimately preventing ischial PUs.

\section{ACKNOWLEDGMENTS}

We would like to thank Mr. John Bycroft for helping recruit subjects and Professor Satsue Hagisawa for her advice during various parts of the study.

This material was based on work supported by a peer-reviewed grant fellowship to Dr. Liang Qin Liu from the Royal National Orthopaedic Hospital, Stanmore, United Kingdom, grant 03/01.

The authors have declared that no competing interests exist.

\section{REFERENCES}

1. Chen HY, Boore JR, Mullan FD. Nursing models and selfconcept in patients with spinal cord injury-A comparison between UK and Taiwan. Int J Nurs Stud. 2005;42(3):255-72. [PMID: 15708013]

2. Bryne DW, Salzberg CA. Major risk factors for pressure ulcers in the spinal cord disabled: A literature review. Spinal Cord. 1996;34(5):255-63. [PMID: 8963971]

3. Ash D. An exploration of the occurrence of pressure ulcers in a British spinal injuries unit. J Clin Nurs. 2002;11(4): 470-78. [PMID: 12100643]

4. Tam EW, Mak AF, Lam WN, Evans JH, Chow YY. Pelvic movement and interface pressure distribution during manual wheelchair propulsion. Arch Phys Med Rehabil. 2003; 84(10):1466-72. [PMID: 14586913]

5. Raghavan P, Raza WA, Ahmed YS, Chamberlain MA. Prevalence of pressure sores in a community sample of spinal injury patients. Clin Rehabil. 2003;17(8):879-84. [PMID: 14682560]

6. Bennett G, Dealey C, Posnett J. The cost of pressure ulcers in the UK. Age Ageing. 2004;33(3):230-35. [PMID: 15082426]

7. Mawson AR, Biundo JJ Jr, Neville P, Linares HA, Winchester Y, Lopez A. Risk factors for early occurring pressure ulcers following spinal cord injury. Am J Phys Med Rehabil. 1988;67(3):123-27. [PMID: 3377890]

8. National Spinal Cord Injury Statistical Center. The 2005 annual statistical report for the model spinal cord injury care systems. Birmingham (AL): National Spinal Cord Injury Statistical Center; 2005. p. 119-22.

9. Bogie KM, Nuseibeh I, Bader DL. Early progressive changes in tissue viability in the seated spinal cord injured subject. Paraplegia. 1995;33(3):141-47. [PMID: 7784116]

10. Guttmann L. Spinal cord injuries: Comprehensive management and research. 2nd ed. London (England): J. B. Lippincott; 1976. p. 244.

11. Ferguson-Pell MW, Wilkie IC, Reswick JB, Barbenel JC. Pressure sore prevention for the wheelchair-bound spinal injury patient. Paraplegia. 1980;18(1):42-51. [PMID: 7375126]

12. Coggrave MJ, Rose LS. A specialist seating assessment clinic: Changing pressure relief practice. Spinal Cord. 2003; 41(12):692-95. [PMID: 14639449]

13. Sachse RE, Fink SA, Klitzman B. Comparison of supine and lateral positioning on various clinically used support surfaces. Ann Plast Surg. 1998;41(5):513-18. [PMID: 9827955] 
14. Bain D, Ferguson-Pell MW, McLeod A. Evaluation of mattresses using interface pressure mapping. J Wound Care. 2003;12(6):231-35. [PMID: 12838601]

15. Levine SP, Kett RL, Cederna PS, Brooks SV. Electric muscle stimulation for pressure sore prevention: Tissue shape variation. Arch Phys Med Rehabil. 1990;71(3):210-15. [PMID: 2180391]

16. Levine SP, Kett RL, Cederna PS, Bowers LD, Brooks SV. Electrical muscle stimulation for pressure variation at the seating interface. J Rehabil Res Dev. 1989;26(4):1-8. [PMID: 2600864]

17. Levine SP, Kett RL. Tissue shape and deformation as a characterization of the seating interface. In: Proceedings of the Annual International Conference of the IEEE Engineering in Medicine and Biology Society; 1989 Nov 9-12; Seattle, WA. New York: IEEE; 1989. p. 851-52.

18. Levine SP, Kett RL, Wilson BA, Cederna PS, Gross MD, Juni JE. Ischial blood flow of seated individuals during electrical muscle stimulation. In: Proceedings of the Tenth Annual Conference on Rehabilitation Technology; 1989; San Jose, CA. Washington (DC): RESNA; 1987. p. 642-44.

19. Kett RL, Levine SP, Wilson BA, Gross MD. Ischial blood flow in the skin of seated individuals during electrical muscle stimulation. In: Proceedings of the Third International Conference on Rehabilitation Technology; 1988; Arlington, VA. p. 324-25.

20. Bogie KM, Triolo RJ. Effects of regular use of neuromuscular electrical stimulation of tissue health. J Rehabil Res Dev. 2003;40(6):469-75. [PMID: 15077659]

21. Lippert-Gruner M. Gluteal neuromuscular stimulation in therapy and prophylaxis of recurrent sacral pressure ulcers. Spinal Cord. 2003;41(6):365-66. [PMID: 12746744$]$

22. Sheriff MK, Shah PJ, Fowler C, Mundy AR, Craggs MD. Neuromodulation of detrusor hyper-reflexia by functional magnetic stimulation of the sacral roots. Br J Urol. 1996; 78(1):39-46. [PMID: 8795398]

23. Liu LQ, Craggs MD, Nicholson GP, Knight SL, Chelvarajah R, Gall A, Middleton FR, Ferguson-Pell MW. Pressure changes under the ischial tuberosities of seated individuals during sacral nerve root stimulation. J Rehabil Res Dev. 2005;43(2):209-18.

24. Barker AT, Freeston IL, Jalinous R, Jaratt JA. Magnetic stimulation of the human brain and peripheral nervous system: An introduction and the results of an initial clinical evaluation. Neurosurgery. 1987;20(1):100-109. [PMID: 3808249]

25. Brindley GS, Polkey CE, Rushton DN. Sacral anterior root stimulators for bladder control in paraplegia. Paraplegia. 1982;20(6):365-81. [PMID: 6984503]

26. Brindley GS. The first 500 patients with sacral anterior root stimulator implants: General description. Paraplegia. 1994; 32(12):795-805. [PMID: 7708419]
27. Brindley GS, Rushton DN. Long-term follow-up of patients with sacral anterior root stimulator implants. Paraplegia. 1990;28(8):469-75. [PMID: 2263403]

28. Hagisawa S, Ferguson-Pell MW, Cardi M, Miller SD. Assessment of skin blood content and oxygenation in spinal cord injured subjects during reactive hyperemia. J Rehabil Res Dev. 1994;31(1)1-14. [PMID: 8035356] Erratum in: J Rehabil Res Dev. 1994;31(2):178.

29. Ferguson-Pell MW, Hagisawa S. An empirical technique to compensate for melanin when monitoring skin microcirculation using reflectance spectrophotometry. Med Eng Phys. 1995;17(2);104-10. [PMID: 7735638]

30. Sprigle S, Linden M, Riordan B. Characterizing reactive hyperemia via tissue reflectance spectroscopy in response to an ischemic load across gender, age, skin pigmentation and diabetes. Med Eng Phys. 2002;24(10):651-61.

[PMID: 12460724$]$

31. Feather JW, Hajizadeh-Saffar M, Leslie G, Dawson JB. A portable scanning reflectance spectrophotometer using visible wavelengths for the rapid measurement of skin pigments. Phys Med Biol. 1989;34(7):807-20. [PMID: 2780799]

32. Feather JW, Ellis DJ, Leslie G. A portable reflectometer for the rapid quantification of cutaneous haemoglobin and melanin. Phys Med Biol. 1988;33(6):711-22. [PMID: 3406055]

33. Schubert V. The influence of local heating on skin microcirculation in pressure ulcers, monitored by a combined laser Doppler and transcutaneous oxygen tension probe. Clin Physiol. 2000;20(6):413-21. [PMID: 11100387]

34. Oliver JL, Slade JM, Dudley GA, McCully KK. Blood flow and muscle fatigue in SCI individuals during electrical stimulation. J Appl Physiol. 2003;94(2):701-8. [PMID: 12391070]

35. Schubert V, Fagrell B. Postocclusive reactive hyperemia and thermal response in the skin microcirculation of subjects with spinal cord injury. Scand J Rehabil Med. 1991; 23(1):33-40. [PMID: 2035001]

36. Mawson AR, Siddiqui FH, Connolly BJ, Sharp CJ, Summer WR, Biundo JJ Jr. Sacral transcutaneous oxygen tension levels in the spinal cord injures: Risk factors for pressure ulcers? Arch Phys Med Rehabil. 1993;74(7):745-51. [PMID: 8328898]

37. Kindig CA, Richardson TE, Poole DC. Skeletal muscle capillary hemodynamics from rest to contractions: Implications for oxygen transfer. J Appl Physiol. 2002;92(6):2513-20. [PMID: 12015367$]$

38. Scremin OU, Cuevas-Trisan RL, Scremin AM, Brown CV, Mandelkern MA. Functional electrical stimulation effect on skeletal muscle blood flow measured with H2(15)0 positron emission tomography. Arch Phys Med Rehabil. 1998;79(6):641-46. [PMID: 9630142]

39. Janssen TW, Hopman MT. Blood flow response to electrically induced twitch and tetanic lower-limb muscle contractions. Arch Phys Med Rehabil. 2003;84(7):982-27. [PMID: 12881821] 
40. Mills KR. Biophysics of magnetic stimulation. In: Mills KR, editor. Magnetic stimulation of human nervous system. Oxford (England): Oxford University Press; 1999. p. 7-26.

41. Creasy GH. Electrical stimulation of the sacral roots for micturition after a spinal cord injury. Urol Clin North Am. 1993;20(3):505-15. [PMID: 8351775]
42. Koldewijn EL, Van Kerrebroeck PE, Rosier PF, Wijkstra H, Debruyne FM. Bladder compliance after posterior sacral root rhizotomies and anterior sacral root stimulation. J Urol. 1994;151(4):955-60. [PMID: 8126835$]$

Submitted for publication August 8, 2005. Accepted in revised form February 23, 2006. 